\title{
Darier's Disease: Report Of A New Case With A Rare Clinical Appearance
}

\author{
A Darjani, A Ramezanpour
}

\section{Citation}

A Darjani, A Ramezanpour. Darier's Disease: Report Of A New Case With A Rare Clinical Appearance. The Internet Journal of Dermatology. 2001 Volume 1 Number 2.

DOI: $\underline{10.5580 / 5 \mathrm{a} 0}$

\begin{abstract}
Patient with localized keratotic lesions and revealing histologic features of dyskeratotic acantholysis have been rarely reported. There is still some controversy regarding the appropriate nosologic placement of this entity. Some believe it represent a variant of epidermal nevus, while others argue it is a genetic mosaic of generalized Darier's Disease. We report a case of a 67-yearsold man who presented with a 1-year history of pruritic, reddish-brown papules on the abdomen. The lesions resolved in the winter and again occurred in the summer months. Physical exam revealed reddish-brown papules with verrucous texture on the abdomen. There were no other cutaneous and membranous signs. Diagnosis of Darier's Disease was histologically evident.
\end{abstract}

\section{CASE REPORT}

A 67-year-old man presented with reddish-brown papules.(Fig. 1) The patient presented with a 1-year generalized pruritus (specially the abdomen. Subsequent, red papules occurred which resolved after a while. Six months later (in the summer), lesions occurred again in the same areas. Physical examination revealed papules on the abdomen, longitudinal band and slightly subungual hyperkeratosis of the left 4th fingernail. General physical examination was normal. Other family members, including his 15-year-old son and 21-year-old daughter had no problems. 


\section{Figure 1}

Figure $1 \mathrm{a}$ and $\mathrm{b}$ : Bilateral reddish-brown papules on the abdomen.

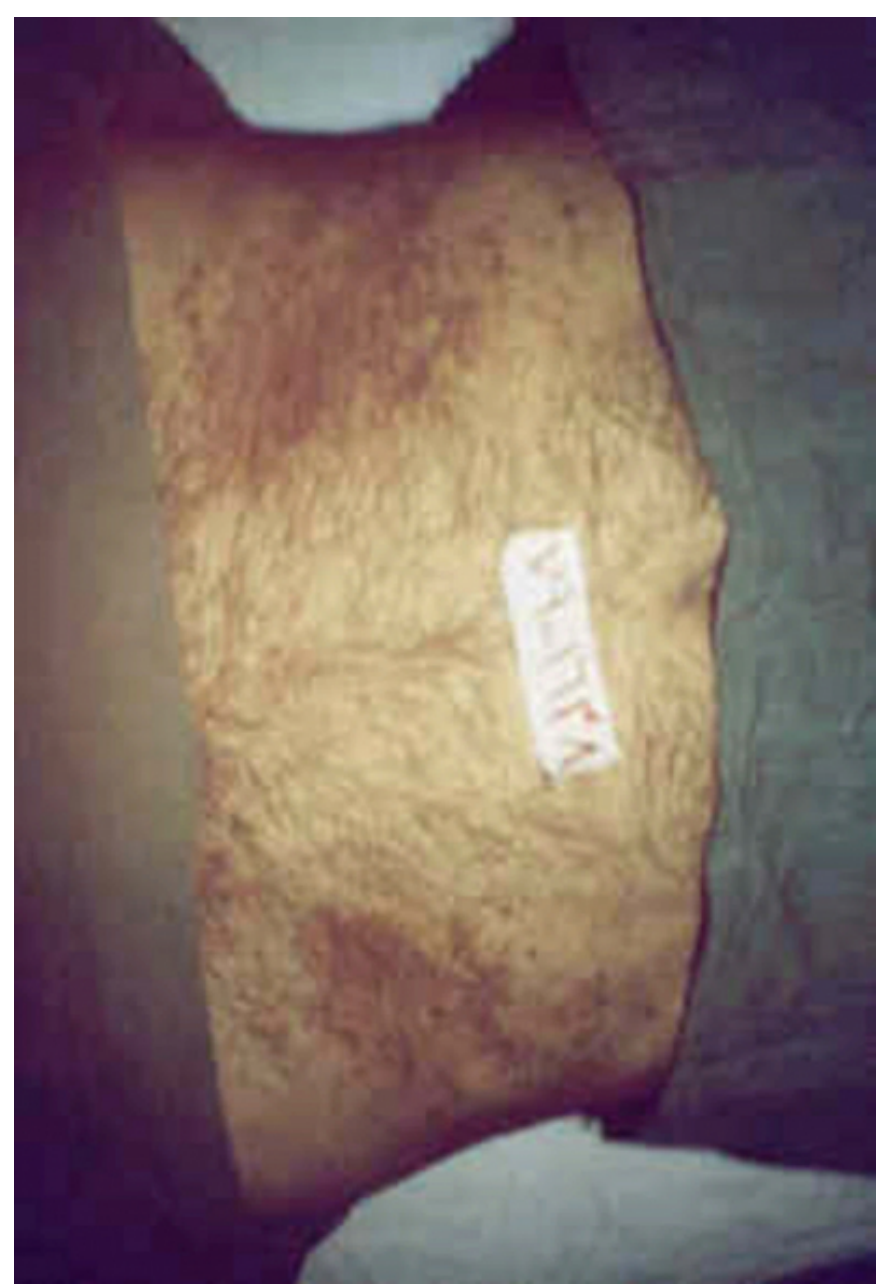

\section{Figure 2}

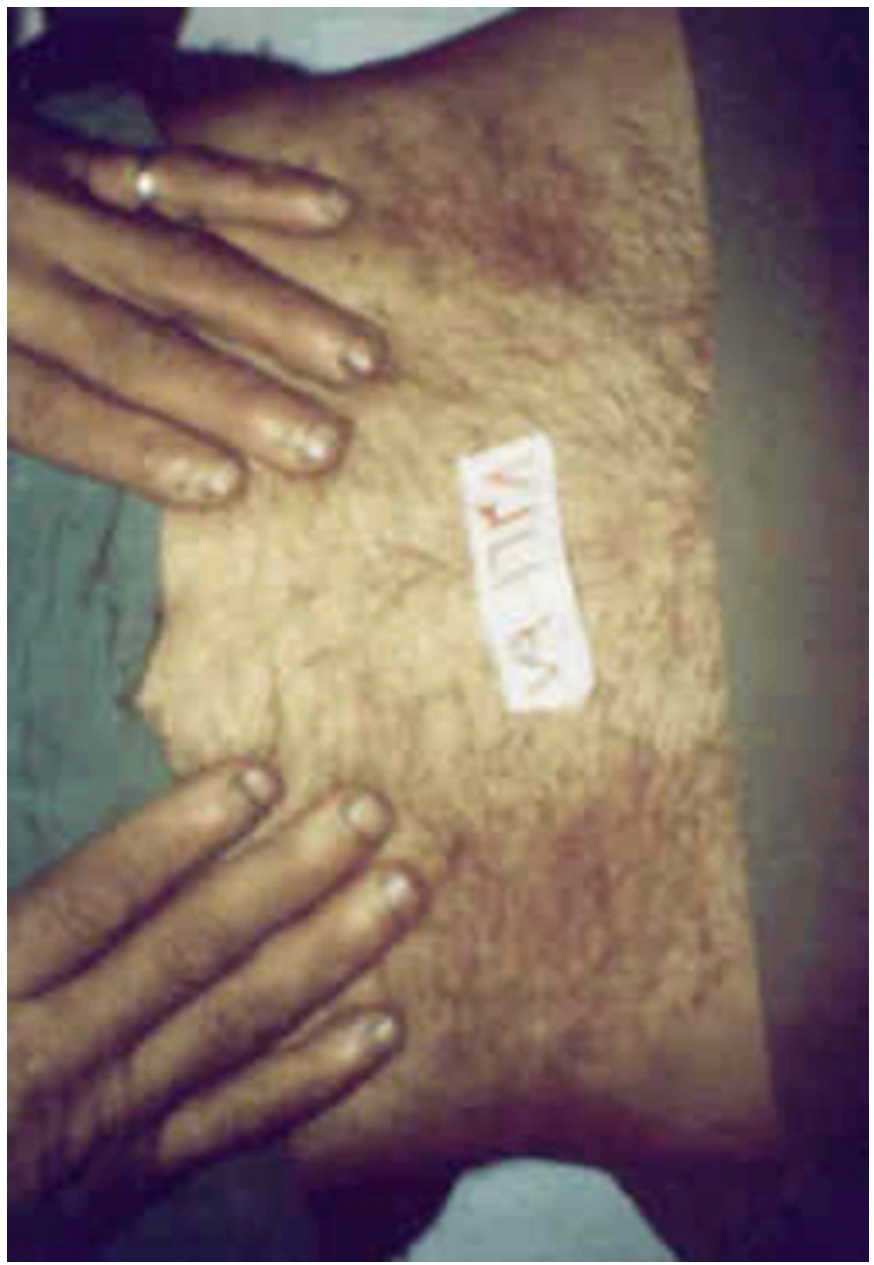

Initial diagnosis was lichen simplex, wart, confluent and reticulated papillomatosis. Biopsy was obtained and showed acanthosis, papillomatosis, hyperkeratosis, and suprabasal clefts in the epidermis. The underlying dermal papillae, covered by a single layer of epithelium, project into these clefts forming villus-like structures. Two types of dyskeratotic cells were seen: corps ronds are predominantly located in stratum granulosum and corps grain are mostly located in stratum corneum. The dermis had mild nonspecific infiltration.(Fig. 2,3,4) 


\section{Figure 3}

Figure 2: Acantholysis, papillomatosis, hyperkeratosis, and suprabasal clefts.

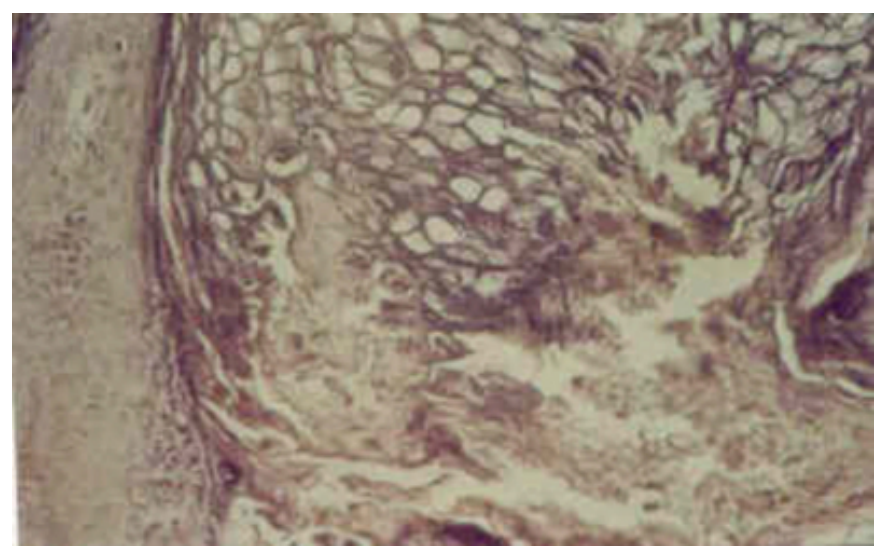

\section{Figure 4}

Figure 3: Corps rond and grain

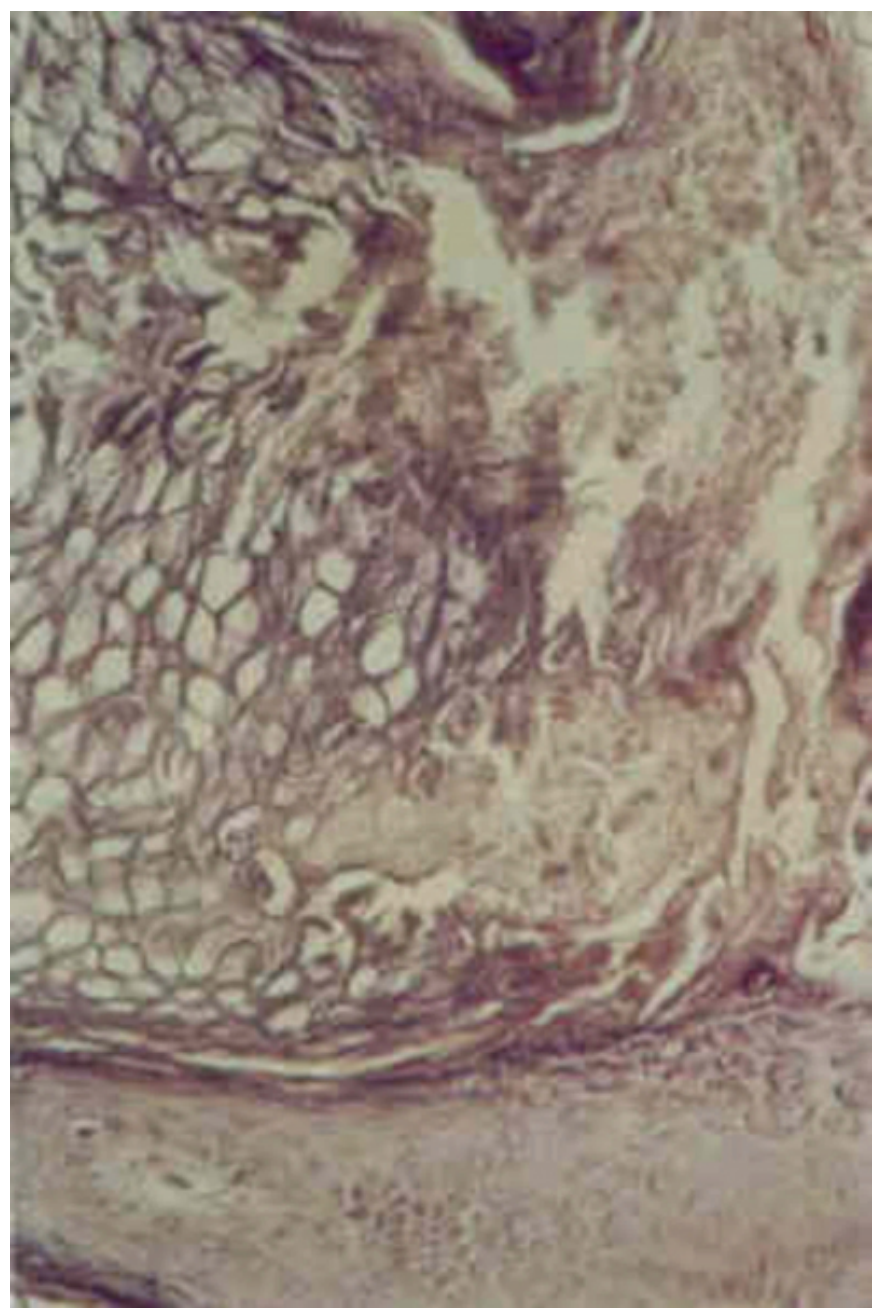

\section{Figure 5}

Figure 4: Clefts in the epidermis

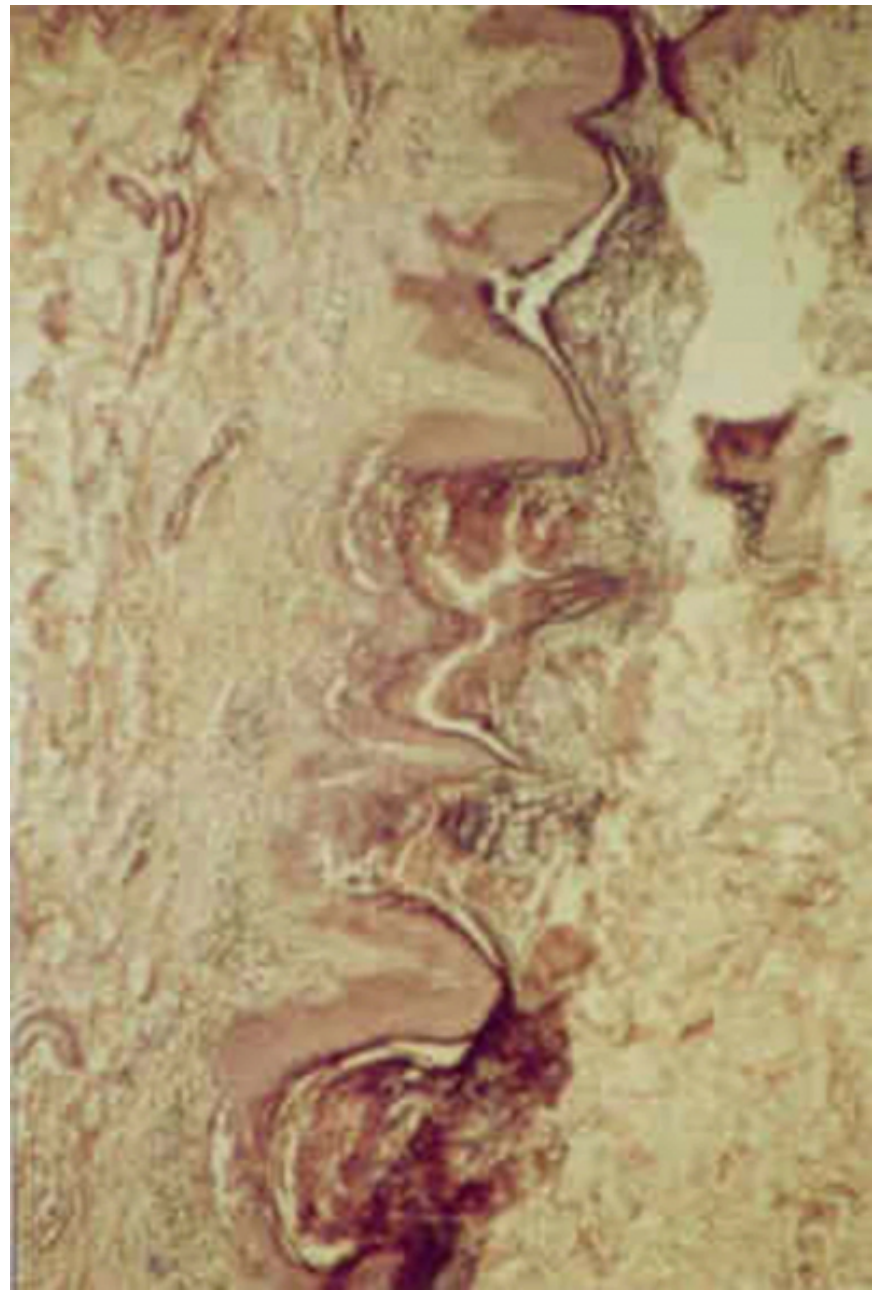

\section{DISCUSSION}

Darier,s disease is an inherited skin condition with autosomal dominant transmission. The prevalence of the disease has been estimated at 1/50,000-100,000. $\left({ }_{1,2}\right)$ The disease almost is sporadic and occasionally develops from spontaneous mutations in the gene of the disease. $\left({ }_{3}\right)$ Pathogenesis of the disease is unknown, but abnormalities of structural proteins may underline the deficiency. $\left(_{4}\right)$

The disease is characterized by itchy reddish-brown keratotic papules primarily in a seborrheic distribution. But other types are reported such as hypertrophic, vesicolobulous, and linear.(3) About $80 \%$ of the patients have mild flexural involvement in the axillae, groin, or in submammary skin in women.(3) Nearly all patients have nail dystrophy, palmar pits, and acral keratosis.(3) The nail changes include of short and wide nail, longitudinal bands, and a fragility of the nails, v-shaped notches at the free edge, red and white lines on the nail plate and subungual 
hyperkeratosis.(3)

Mucosal lesions are reported. They are uncommon, but it they are seen in many familes, and are reported in about $15-50 \%$ of the patients. They appear as white papules with central depression, or with cobble-stone appearance on the palate, gingival, and buccal mucosa.( $\left.{ }_{5}\right)$

Heat, sunlight, sweating, and lithium and steroid therapy exacerbate the disease. $(6,7,8)$

The severity of the disease varies. There is a report of Japanese family in which two sisters and their mother with Darier`s Disease showed apparent heterogenous clinical severity.( $\left.{ }_{9}\right)$

Linear or zosteriform distributions are reported in $10 \%$ of cases. The majority are probably example of acantholytic dyskeratotic epidermal neavi with no family history or evidence of Darier's Disease elsewhere. $\left({ }_{10},{ }_{11},{ }_{12}\right)$ There are a few reports of localized Darier`s Disease, occurring with equal frequency in males and females, the average age at onset was 27 years, and the most frequent site of involvement was the trunk. $\left.{ }_{13}\right)$ Our patient differed from previous cases in that he had bilateral distribution and was elder.

There are various reports of its pathogenesis. Some describe them as epidermal variant. $\left({ }^{14}\right)$ Other reports suggest that it is a genetic mosaic of generalized Darier`s Disease.(13)

\section{CORRESPONDENCE TO}

Afshar Ramezanpour MD., Department of Dermatology,
RAZI Hospital, Medical University of GILAN, Gilan, IRAN +98,131,5550028; E-mail:drafsharpr@yahoo.com

\section{References}

1. Wilkson JD, Marseden RA, Dawber RPR. Review of Darier`s Disease in the oxford region. Br J Dermatol 1997;97(supp 15):15-16

2. Burg SM, Wilkinson JD. Darier-white disease: A review of the clinical features in 163 patients. J Am Acad Dermatol 1992;27:40-50

3. Burg SM, Cederholm-Williams SA, Garrod DR, Ryan TJ. Cell adhesion in Haily-Haily disease and Darier's disease immunocytological and explant-tissue-culture studies.Br J Dermatol 1991;125:426-435

4. Macleod RT, Munro CS. The incidence and distribution lesions in patients with Darier`s Disease. Br Dent J 1991;171:133-6

5. Baba T, Yaoita H. UV radiation and keratosis follicularis. Arch Dermatol 1984;120:1484-7

6. Milton GP, Peek GL,Fuji GL. Exacerebation of Darier`s diseas by lithium carbonate. J Am Acad Dermatol 1990;23:926-8

7. Espy PD, Ston S, Jally Hw JR. Hormonal dependency in Darier's disease. Cutis 1976;17:315-20

8. Inada M, Shimizu H, Yamada S, Sasaki Y, Nishikawa T. Three cases of Darier's disease in a family showing marked heterogeneous clinical severity. Dermatology J 1999;198(2): 167-70

9. Cambiaghi S, Brusasco A, Grimalt R, ET AL.

Acantholytic dyskeratotic epidermal nevus as a mosaic form of Darier's disease. J Am Acad Dermatol 1995;32:284-6 10. Munro CS, Cox NH. An acantholytic epidermal nevus with other features of Darier`s diseaseon the same side of the body. Br J Dermatol 1992;127:168-71

11. Gautam RK, et al. Localized Darier`s disease and it nosologic status. Int J Dermatol 1996;35:355

12. Malley MP, Haake A, Golsmith L, Berg D. Localized Darier`s disease. Implication for genetic studies. Arch Dermatol 1997;133(9):1134-8

13. Starnik TM, Woerdman MJ. Unilateral systematized keratosis follicularis. A variant of Darier`s disease or an epidermal naevus(acantholytic dyskeratotic epidermal naevus)? Br J Dermatol 1981;105(2):207-14 


\section{Author Information}

Abbas Darjani, Clinical Assistant Professor

dermatology, Razi Hospital, Medical University

Afshar Ramezanpour, Resident

Dermatology, Razi Hospital, Medical University 